\title{
Weight, height and body mass index of children and adolescents living at moderate altitude in Colombia
}

\author{
Edilberto Díaz Bonilla, Master ${ }^{a}$,Claudia L. Torres Galvis, Mastera, \\ Rossana Gómez Campos, M.D. .,c, Miguel de Arruda, M.D.c, \\ Jaime Pacheco Carrillo, M.D. ${ }^{d}$ and Marco Cossio Bolaños, M.D. ${ }^{c e, f}$
}

\begin{abstract}
Introduction. There is increasing concern over the study of physical growth in different regions of the world, although altitude is not considered an adjustment factor.

Objectives. Compare physical growth variables and body mass index (BMI) patterns with the Centers for Disease Control and Prevention (CDC) 2012 reference data and develop percentiles for children and adolescents.

Methodology.School childrenliving at moderate altitudeinBogotá(Colombia)werestudied. Their weight and height were evaluated and their BMI was calculated. Anthropometric variables were compared against reference data of the CDC-2012, Brazil, Peru and Argentina. Curves were constructed using the least mean square (LMS) method.
\end{abstract}

a. Universidad Pedagógica y Tecnológica de Colombia, Tunja (Boyacá), Colombia.

b. Universidad Autónoma de Chile, Talca, Chile.

c. School of Physical Education, Universidade Estadual de Campinas, São Paulo, Brazil.

d. Universidad del BíoBío, Chillán, Chile.

e. Department of Physical Activity Science, Universidad Católica del Maule, Talca, Chile.

f. Universidad Nacional de San Agustín, Arequipa, Peru.

E-mail address:

Marco A. Cossio

Bolaños, M.D.: mcossio1972@hotmail. com

Funding:

None.

Conflict of interest: None.

Received: 5-4-2017

Accepted: 9-19-2017

\section{INTRODUCTION}

Physical growth (PG) and human development are characterized by their intrapopulation and interpopulation heterogeneity. ${ }^{1}$ This is the product of continued, complex interactions among genes as well as with different mesogenic conditions. ${ }^{2}$

As a matter of fact, studying physical growth among populations is relevant as, for a long time, it has been the primary goal in the fields of human biology and public health. It has even been suggested that weight and height are major classic indicators in assessing PG in children and adolescents. ${ }^{3}$

In this context, very few studies conducted in Colombia ${ }^{4}$ have prioritized the study of PG in different geographic regions, without considering altitude as an adjustment variable. As a matter of fact, altitude is an important variable that plays a major role in the study of PG, which has been widely surveyed in different research efforts. ${ }^{5,6}$ Some studies conducted at moderate altitude have evidenced the existence of significant differences in the PG patterns of children and adolescents. ${ }^{7}$

This information suggests the influence of population-specific environmental, cultural and genetic differences; hence, the weight, height and BMI of children and adolescents at moderate altitude in Bogotá (Colombia) are likely to differ from the US Centers for Disease Control and Prevention 2012 reference data (CDC-2012) and other South America regional standards.

Overall, regional surveys aimed to compare PG against international references use the $C_{D C}^{8,9}$ and the 
World Health Organization $(\mathrm{WHO})^{10}$ reference data. In essence, these references are valuable clinical practice tools for individual assessment and follow-up of PG. In fact, there is additional concern in public health over childhood obesity, ${ }^{11}$ as in recent years it has increased in children and adolescents in South America due to the nutrition transition phenomenon. ${ }^{12}$

Hence, this study has the following aims: a) to compare growth variables (weight and height) and BMI patterns against the CDC-2012 reference data and other international studies, and b) to develop weight, height and BMI percentiles for school-age children and adolescents living at moderate altitude in Colombia.

\section{METHODOLOGY}

\section{Type of study and sampling}

We conducted a descriptive, cross-sectional survey of school children living at moderate altitude in Bogotá (Colombia). Ages ranged from 6.0 to 17.9 years. School children were recruited from a public education institution located at 2640 meters above sea level attended by children of mestizo (Spanish and indigenous) origin, from 12 Bogotá districts. We used non-probability sampling (quotas). School children came from middle class backgrounds and their diets were based on the daily intake of products such as cornmeal, potato, banana, cabbage and coffee.

Students who had physical disabilities or for whom informed consent had not been obtained were excluded. School children for whom informed consent and assent were obtained and measurements had been completed were included. Permission was given by the school Principal's Office for the conduct of the study, which was performed in accordance with the Declaration of Helsinki and Resolution 8430 of the Ministry of Health and Social Protection of Colombia. The study was further approved by the local Ethics Committee.

\section{Procedures}

The data collection procedure comprised three stages. Firstly, we explained the objectives and variables to be evaluated to the parents, who were asked to sign the parental informed consent form. Secondly, evaluation cards were sorted by age, sex, school level (primary or secondary), school hours and names of the persons performing the assessment. Thirdly, evaluations were conducted during school hours from 7:00 am to noon, Mondays through Fridays, over the month of October 2013.
Assessments were carried out at the school facilities by eight teachers (four men and four women) who had ample experience in anthropometric measurement taking and had received previous training from the International Society for the Advancement of Kinanthropometry (ISAK). ${ }^{13}$ The intra- and interobserver technical error of measurement (TEM) was between $0.82 \%$ and $1.5 \%$.

Variables such as weight and height were measured with the students wearing light clothing (shorts and shirts) and no shoes, as required by the ISAK standardized protocol. ${ }^{13}$ Body weight (in $\mathrm{kg}$ ) was measured using a digital scale (Tanita UK Ltd.) with a weight capacity of $0-150 \mathrm{~kg}$ and a precision of $100 \mathrm{~g}$. Height was measured with a portable stadiometer (Seca $\mathrm{GmbH} \& \mathrm{Co}$. KG, Hamburg, Germany), with a precision of $0.1 \mathrm{~mm}$. The BMI was calculated by applying the formula $\mathrm{BMI}=$ weight $(\mathrm{kg}) /$ height $^{2}(\mathrm{~m})$. Age categories were organized in intervals of 6.0 to 6.9 years, 7.0 to 7.9 years, and so forth until 17.0 to 17.9 years.

Weight, height and BMI comparisons were made against international references: CDC2012 reference data, ${ }^{9}$ the reference suggested by Alfaro et al., ${ }^{1}$ for Jujuy (Argentina), and the proposed standards for Campinas (Brazil) ${ }^{14}$ and the central region of Peru. ${ }^{15}$ We opted for these references because they were the latest available ones and exhibited regional characteristics with similar human development indexes (HDI) in recent years.

\section{Statistical analysis}

Normal data distribution was verified using the Kolmogorov-Smirnov test. Then, the descriptive statistics of arithmetic mean, standard deviation (SD) and range were calculated. Differences between sexes were verified using the $t$ test for independent samples. Differences between the CDC-2012 reference values and mean values and \pm SD values for Bogotá (Colombia) were determined by the $t$ test for related samples. The level of significance was set at 0.05 .

Comparisons to international references (Argentina, Brazil and Peru) were graphically represented using the $50^{\text {th }}$ percentile. Percentiles (p5, p10, p15, p50, p85, p90 y p95) for weight, height and BMI by age range and sex were developed using the LMS method, ${ }^{16}$ through which specific smoothed percentile curves can be obtained: L (lambda, asymmetry), M (mu, median), and S (sigma, coefficient of variation). We used the LMS Chart Maker version 2.3 software. ${ }^{17}$ Statistical calculations were performed 
using Excel spreadsheets and the SigmaStat and SPSS 16.0 softwares.

\section{RESULTS}

The variables characterizing the 2241 school children studied (1082 boys and 1159 girls) are shown in Table 1. There were no differences in the body weight of both sexes from 6 to 14 years of age. Boys aged 15 to 17 years, however, showed greater body weight than their counterparts $(\mathrm{p}<0.05)$. As far as weight is concerned, there were no significant differences at early ages (6 to 8 years), while at intermediate ages, girls were taller until the age of $12(\mathrm{p}<0.05)$. At advanced ages, boys showed greater height as compared to girls $(p<0.05)$. With regard to the BMI, there were no significant differences between both sexes for the ages of 6 to 12 years. Between the ages of 13 to 18 years, however, girls exhibited significantly higher values than boys $(\mathrm{p}<0.05)$.

Figure 1 shows weight and height comparisons for Bogotá school children against the CDC-2012 references and the values obtained in other South American surveys. As for body weight, school children of both sexes living in Bogotá exhibited a similar growth pattern from the ages of 6 to 8 years. Then, between the ages of 9 to 17 , values were significantly lower than the CDC-2012 reference values $(p<0.5)$. We further observed that for both sexes body weight values were relatively similar to those of international surveys.

With regard to height, both male and female school children living in Bogotá exhibited lower values at all ages as compared to those of the CDC-2012. As for comparisons with international surveys of South America, similar growth patterns were observed for both sexes, with slight discrepancies across all ages.

Figure 2 compares the BMI in Bogotá school children with international references. In both sexes, values increased with age. There were no significant differences relative to the CDC-2012 references in both sexes from ages 6 to 8 . From ages 9 to 17, differences were significant ( $\mathrm{p}<$ 0.05): Bogotá school children showed lower BMI values. With regard to comparisons with other international surveys, boys exhibited similar behavior at all ages. In girls, this pattern was

TABLE 1. Anthropometric characteristics of school children surveyed $(n=2241)$

\begin{tabular}{|c|c|c|c|c|}
\hline Age (years) & $\begin{array}{c}\text { n } \\
\text { Girls }\end{array}$ & $\begin{array}{c}\text { Weight (kg) } \\
X \pm S D\end{array}$ & $\begin{array}{c}\text { Height (cm) } \\
X \pm S D\end{array}$ & $\begin{array}{c}\text { BMI }\left(\mathrm{kg} / \mathrm{m}^{2}\right) \\
\mathrm{X} \pm \mathrm{SD}\end{array}$ \\
\hline $6.0-6.9$ & 102 & $21.1 \pm 3.9$ & $113.4 \pm 5.7$ & $16.3 \pm 2.0$ \\
\hline $7.0-7.9$ & 88 & $24.2 \pm 3.8$ & $121.6 \pm 4.7$ & $16.3 \pm 1.9$ \\
\hline $8.0-8.9$ & 82 & $27.9 \pm 5.4$ & $127.7 \pm 6.5$ & $17.1 \pm 2.5$ \\
\hline $9.0-9.9$ & 90 & $30.4 \pm 6.3$ & $133.4 \pm 6.4$ & $17.0 \pm 2.7$ \\
\hline 10.0-10.9 & 70 & $34.1 \pm 6.2$ & $140.7 \pm 6.9$ & $18.1 \pm 2.5$ \\
\hline 11.0-11.9 & 101 & $39.6 \pm 8.9$ & $146.5 \pm 6.6$ & $18.3 \pm 3.2$ \\
\hline $12.0-12.9$ & 79 & $41.3 \pm 9.5$ & $151.2 \pm 6.3$ & $19.3 \pm 3.3$ \\
\hline $13.0-13.9$ & 81 & $47.5 \pm 6.5$ & $155.7 \pm 4.9$ & $20.0 \pm 2.8$ \\
\hline $14.0-14.9$ & 96 & $53.2 \pm 8.7$ & $157 \pm 5.7$ & $21.5 \pm 3.1$ \\
\hline $15.0-15.9$ & 114 & $52.8 \pm 6.9$ & $158.2 \pm 5.8$ & $21.1 \pm 2.4$ \\
\hline $16.0-16.9$ & 105 & $52.9 \pm 7.9$ & $157.2 \pm 5.2$ & $21.4 \pm 2.4$ \\
\hline $17.0-17.9$ & 74 & $55.3 \pm 9.8$ & $158.1 \pm 5.5$ & $22.1 \pm 3.4$ \\
\hline \multirow[t]{2}{*}{ Total } & 1082 & $40 \pm 14.0$ & $143.5 \pm 16.6$ & $19.1 \pm 3.4$ \\
\hline & Boys & & & \\
\hline $6.0-6.9$ & 120 & $21.3 \pm 31$ & $114.1 \pm 5.4$ & $16.4 \pm 1.7$ \\
\hline 7.0-7.9 & 90 & $24.4 \pm 3.7$ & $120.9 \pm 5.4$ & $16.6 \pm 2.0$ \\
\hline $8.0-8.9$ & 93 & $27.9 \pm 5.5$ & $126.6 \pm 5.4$ & $17.3 \pm 2.8$ \\
\hline $9.0-9.9$ & 119 & $30.8 \pm 6.2$ & $131.4 \pm 5.7^{*}$ & $17.7 \pm 2.9$ \\
\hline 10.0-10.9 & 86 & $34.1 \pm 7.3$ & $136.5 \pm 6.6^{*}$ & $18.2 \pm 2.8$ \\
\hline $11.0-11.9$ & 106 & $39.1 \pm 7.9$ & $143.8 \pm 7.6^{*}$ & $18.8 \pm 2.9$ \\
\hline 12.0-12.9 & 100 & $42.9 \pm 7.7$ & $149.4 \pm 7.2^{*}$ & $19.2 \pm 2.5$ \\
\hline 13.0-13.9 & 85 & $46.9 \pm 10.1$ & $157.5 \pm 8.4^{*}$ & $18.6 \pm 3^{*}$ \\
\hline $14.0-14.9$ & 98 & $53.6 \pm 10.3$ & $164.5 \pm 6.9^{*}$ & $19.7 \pm 3.2^{*}$ \\
\hline $15.0-15.9$ & 90 & $56.21 \pm 9.6^{*}$ & $167.0 \pm 6.4^{*}$ & $20.1 \pm 3.0^{*}$ \\
\hline $16.0-16.9$ & 91 & $60.1 \pm 9.8^{*}$ & $168.1 \pm 5.9^{*}$ & $20.1 \pm 2.9^{*}$ \\
\hline $17.0-17.9$ & 81 & $61.3 \pm 9.3^{*}$ & $170.9 \pm 5.9^{*}$ & $20.6 \pm 2.9^{*}$ \\
\hline Total & 1159 & $40.8 \pm 15.7$ & $144.8 \pm 20.5$ & $18.7 \pm 3.1$ \\
\hline
\end{tabular}

BMI: body mass index; SD: standard deviation. 
similar at early stages; however, as from the age of 12 years, discrepancies were greater and lower BMI values were recorded.

Percentile distribution for weight, height and BMI by age and sex is shown in Table 2. In all cases, values increased with age. Proposed percentiles were p5, p10, p15, p50, p85, p90 and p95.

Figure 3 shows the graphical comparisons of percentiles (p5, p50 and p95) between the regional curves of Bogotá and those of the CDC-

FIGURE 1. Comparison of mean values and \pm standard deviation of weight and height variables of children and adolescents living in Bogotá (Colombia) with the US Centers for Disease Control and Prevention 2012 reference and 50th percentile discrepancies among South American studies
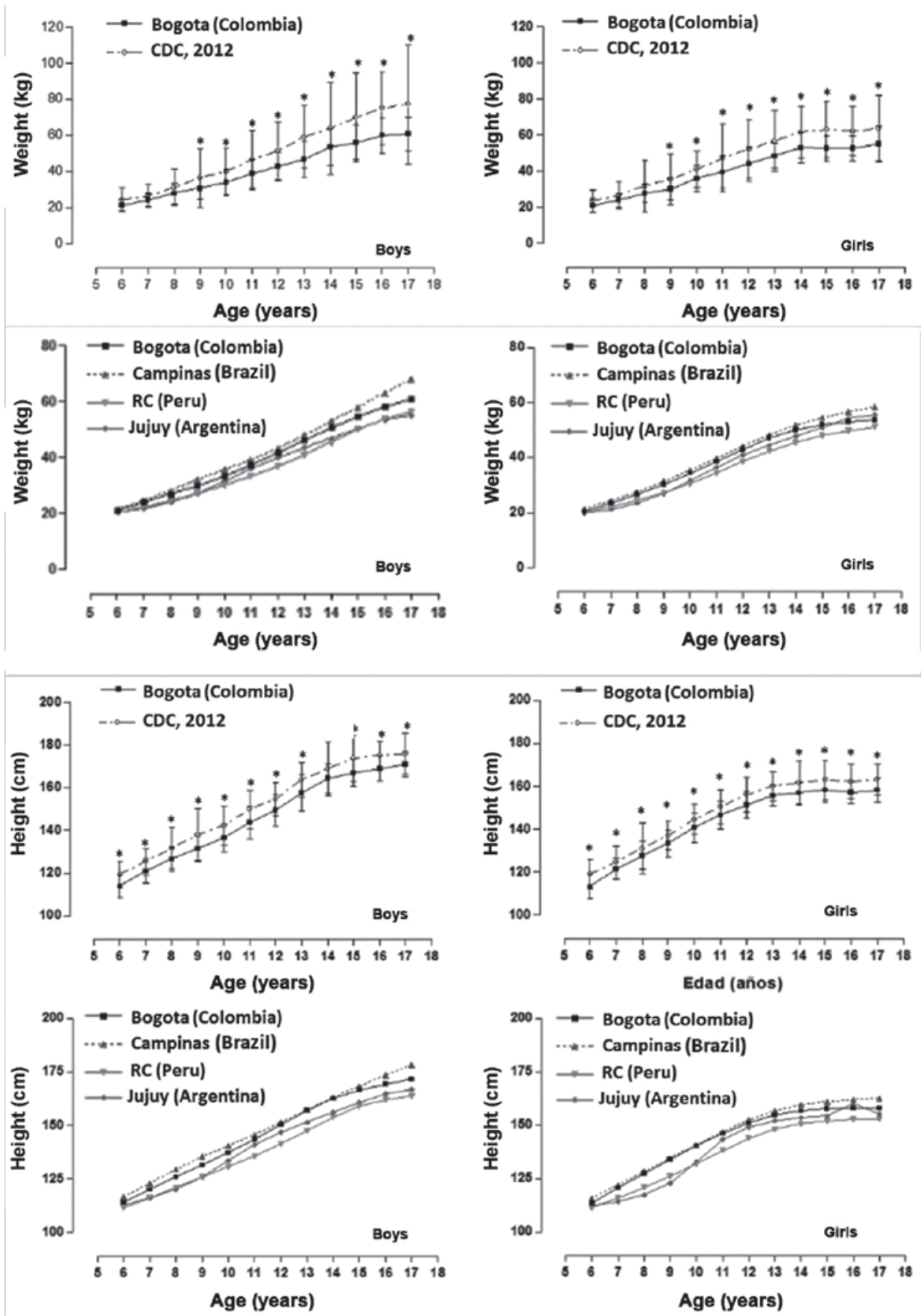

CDC: Centers for Control Disease and Prevention; CR: central region. 
2012. Weight, height and BMI curves exhibited similar patterns to those of the CDC-2012: values increased progressively with chronological age. However, discrepancies were evident at all ages and in p5, p50 and p95.

\section{DISCUSSION}

This study is the first to describe PG in children and adolescents living at moderate altitude in Colombia. Overall, the results analyzed evidenced that school children of both sexes living in Bogotá exhibited lower weight and height than the CDC-2012 reference data.

According to previous surveys, stunted growth in populations at moderate ${ }^{18}$ and high altitudes ${ }^{5}$ is strongly associated with extrinsic (environmental) factors. These results confirm the specific cultural, environmental and genetic differences that these populations are prone to exhibiting. In addition, when compared to other South American surveys, ${ }^{1,4,15}$ results evidenced relatively lower PG patterns.
These findings confirm the discrepancies existing in terms of weight and height among school children in different geographic regions of the world, and it is even possible to observe these differences within one same country in relation to social, cultural and environmental inequalities, as well as lifestyles and nutrient intake among regions. ${ }^{19}$

Hence, the results observed underscore the diversity and difficulty of physical growth in challenging environments. ${ }^{20}$ This highlights the importance of obtaining new descriptions of PG variables and BMI values among populations, particularly in school populations at moderate and high altitudes.

In fact, this information is useful to better understand human biological variation and public health ${ }^{3}$ of children and adolescents as, over the first years of life, monitoring PG by sequential measurement of weight, height and BMI is of the essence. ${ }^{21}$ This is common practice in Latin America, including Colombia, and other parts of the world.

FIGURE 2. Comparison of mean values and \pm standard deviation of body mass index of children and adolescents in Bogotá (Colombia) with the US Centers for Control Disease and Prevention 2012 reference and discrepancies in the $50^{\text {th }}$ percentile with South America surveys
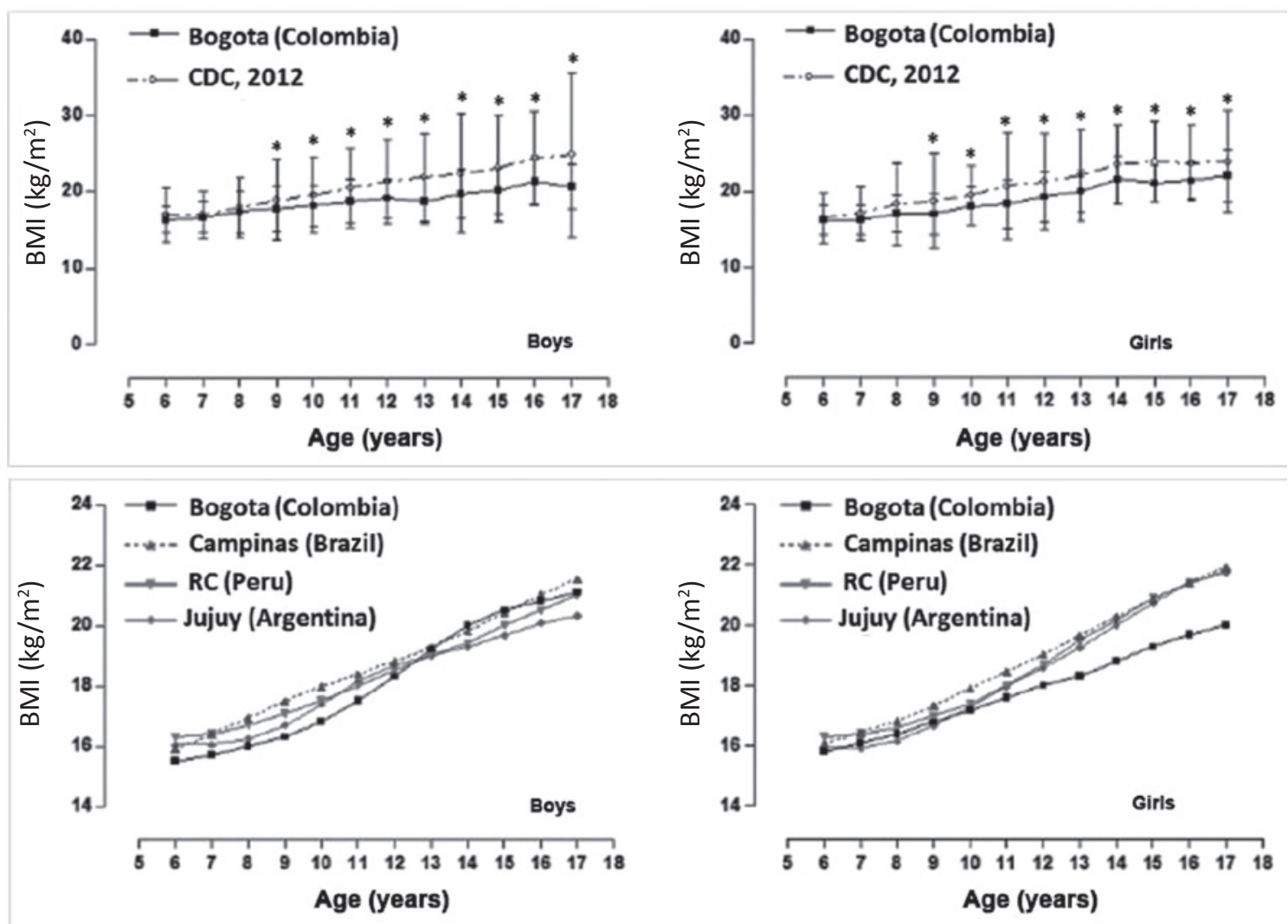

BMI: body mass index; CDC: Centers for Control Disease and Prevention; CR: central region. 
L

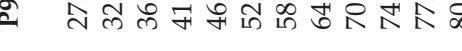

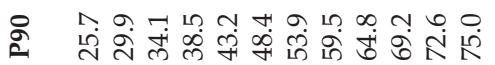

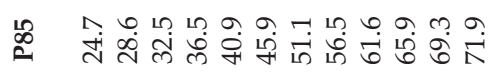

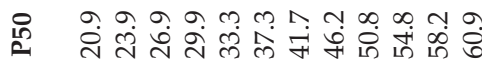

番

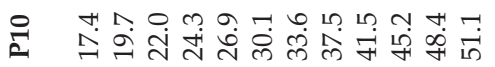

に

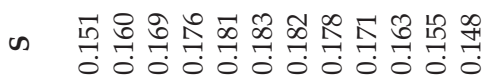

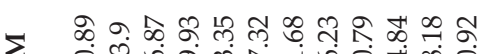

इ तें तें

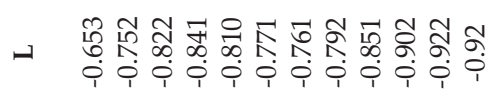

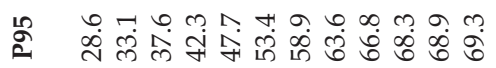

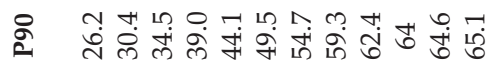

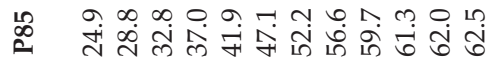

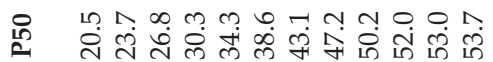

n)

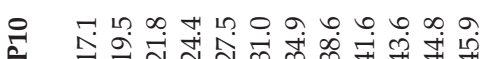

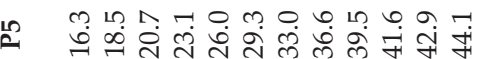

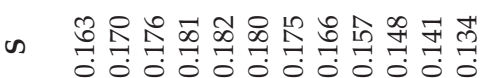

कร กิ ฉ

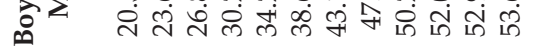

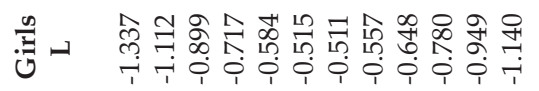

అำ

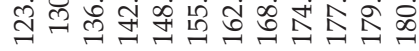

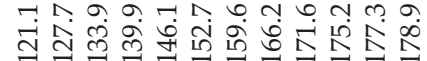

ก ข

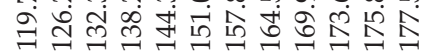

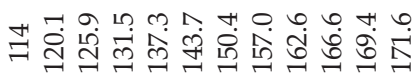

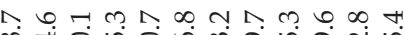

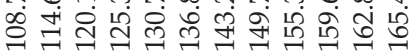

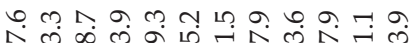

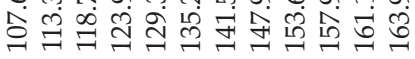

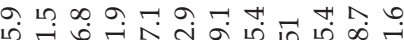

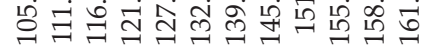

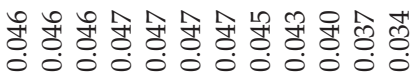

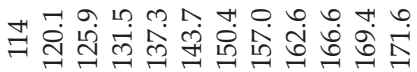

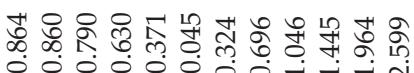

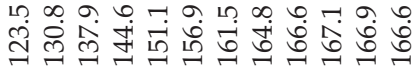

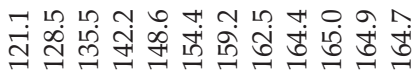

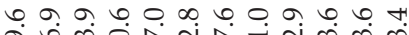

守过

$0 \wedge$ L 0 H n

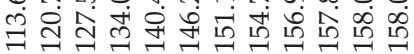

ก้ n

$0 \wedge$ ก

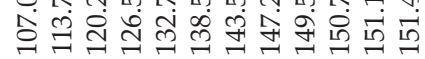

त 2 त

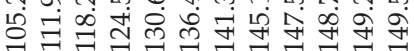

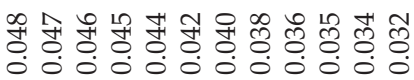

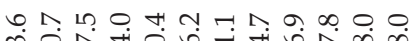

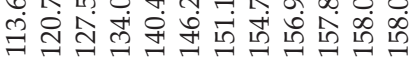

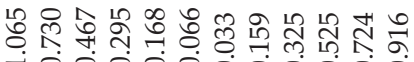
हु

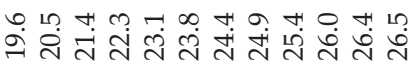

舟

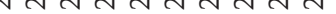
舟

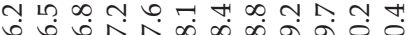

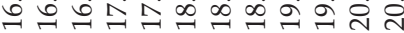

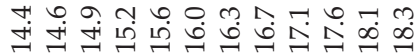

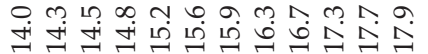

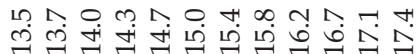

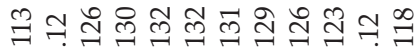
$\circ 00505050.000$

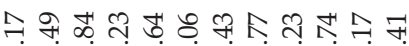

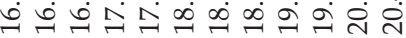

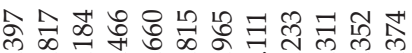

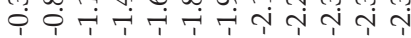

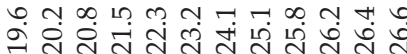
吕 ํㅣㅁ

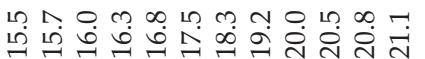

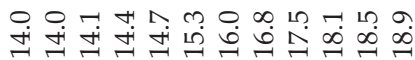

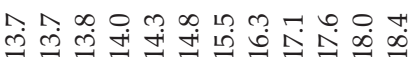
光

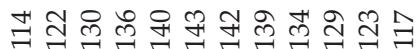

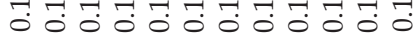

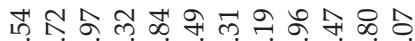

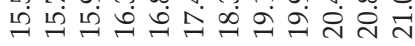

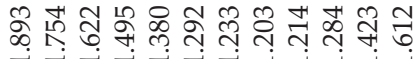
踏

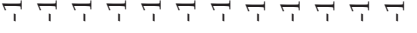
- $a \cdot a$ a

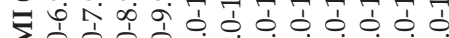

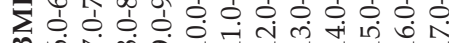


With respect to BMI comparisons against the CDC-2012 reference, results showed that school children living at moderate altitude exhibited similar values at early ages while later on, from ages 9 to 17 years, they were significantly lower. This demonstrates that low weight and height certainly lead to plunging BMI values, as a result of factors inherent to specific ethnic groups that developing countries normally experience (economic, nutritional, cultural and environmental changes).

As a matter of fact, some previous studies have shown that BMI is not applicable to children and adolescents living at moderate altitude ${ }^{18,23}$ since, as an obesity index, it cannot be used in populations having marked height differences, ${ }^{24}$ particularly in populations presenting stunted PG.
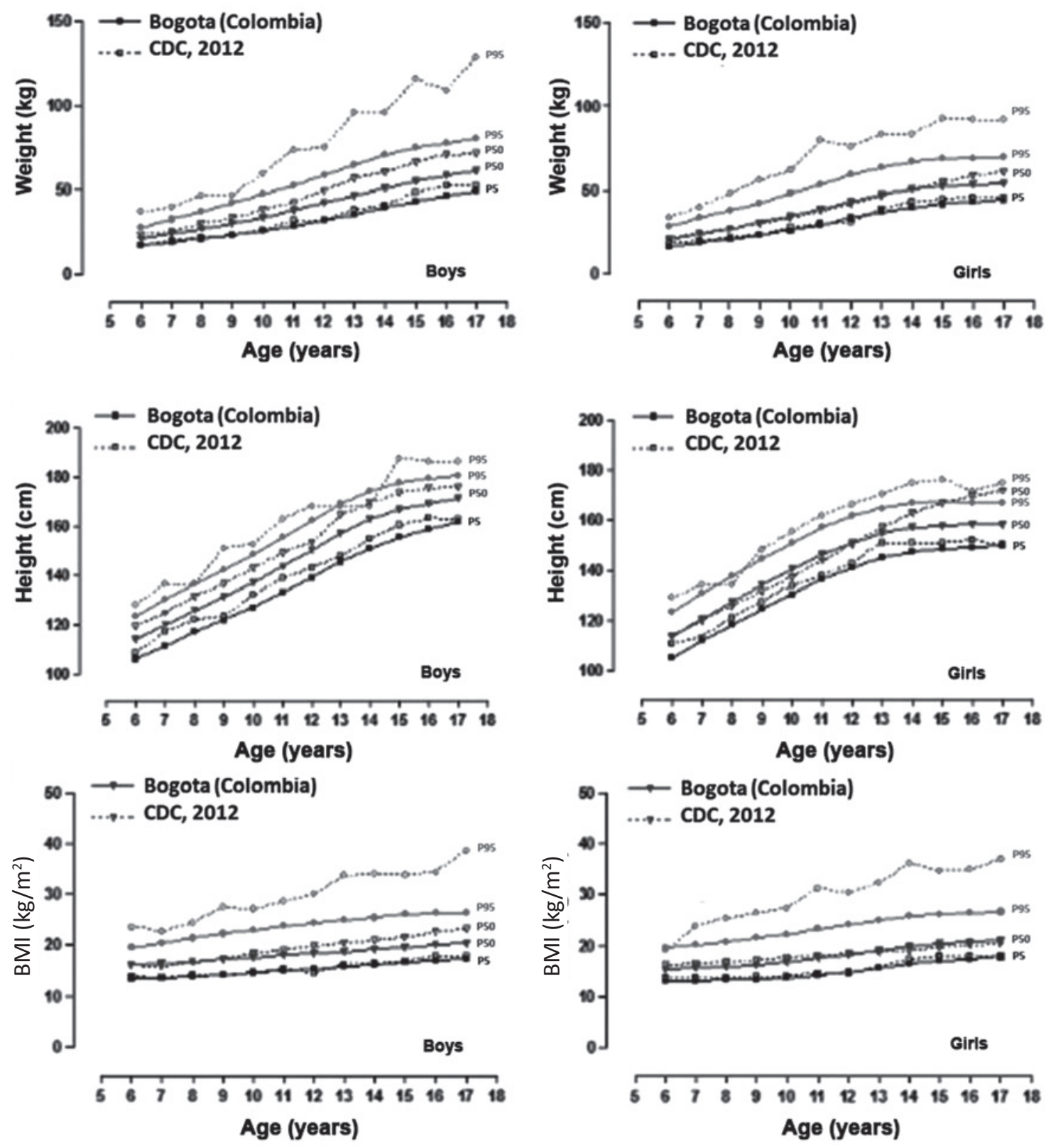

BMI: body mass index; CDC: Centers for Control Disease and Prevention; P: percentile. 
In this sense, the accuracy of BMI to calculate the body fat percentage was the focus of several studies. ${ }^{25,26}$ This notwithstanding, the $\mathrm{WHO}^{27}$ suggests that the BMI be used for identifying and diagnosing overweight and obesity in children and adolescents. In its original design, children born at less than 1500 MASL were included in the sample. ${ }^{28}$ Hence, the PG curves and BMI values proposed by the WHO could not be applied to moderate altitude regions such as Bogotá (2640 MASL).

Consequently, in view of the weight, height and $\mathrm{BMI}$ differences encountered relative to the CDC-2012 reference data and international surveys, we developed weight, height and BMC curves by age and sex to evaluate PG, nutritional status and body adiposity of school children living at moderate altitude in Colombia.

Overall, weight, height and BMI percentiles provide relevant information to infer the nutritional and health status of children and adolescents, ${ }^{29}$ regardless of the geographical region. In addition, they may be used to draw comparisons with other international and/or regional samples of similar characteristics, as the actual value of the curves lies in the fact that they help determine the extent to which physiological needs are met during the growth and motor development process. ${ }^{30}$

For that purpose, percentiles were developed using the LMS method, as it was deemed a valuable tool that represented clear advantages in relation to other traditional calculation methods. ${ }^{31}$ Cut-off points adopted were the same as those used in the CDC 2000, 2012 and 2016..$^{8,9,32}$ These values reflected normal, overweight and obesity categories $(\mathrm{p}<10$, from $\mathrm{p} 10$ to $\mathrm{p} 85$, from $\mathrm{p} 85$ to p95 and p >95), respectively.

In essence, Colombia exhibits diverse orographic and environmental characteristics that render it an attractive country for PG to be studied. In recent years, the HDI in Colombia has been on the increase, as it was 0.711 in 2013, while for Bogotá it stood at $0.911 .^{33}$ These results evidence Colombia's rapid rate of economic growth, which must be a growing concern to monitor PG.

Some study strengths stand out. Assessments were conducted in standard fashion by widely experienced evaluators. In addition, in constructing growth curves, we considered the adjustment for altitude ${ }^{34}$ as well as some criteria suggested by Butte et $\mathrm{al}^{35}$ such as population individual selection criteria, study design, standardized measurements and statistical models. ${ }^{35}$ Sample size, however, was determined by non-probability sampling which, presumably, might limit the results achieved. For future studies, the use of probability sampling is recommended as it might facilitate generalization to other regional contexts in Colombia.

In conclusion, weight, height and BMI variables differ from the CDC-2012 reference data as well as from regional studies of South America. These discrepancies helped build weight and height curves by age and sex to monitor growth in school children living at moderate altitude in Colombia. In this study, the BMI index was used for information purposes because, as an overweight indicator, it is deemed inadequate for school children living at moderate altitude. ${ }^{18}$ Results suggest that it be used and applied in clinical and epidemiolological contexts. http: / / www.reidebihu.net/growth.bogota.php

\section{REFERENCES}

1. Alfaro E, Bejarano I, Dipierri J, et al. Percentilos de peso, talla e índice de masa corporal de escolares jujeños calculados por el método LMS. Arch Argent Pediatr 2004;102(6):431-9.

2. Guimarey LM, Carnese FR, Pucciarelli HM. La influencia ambiental en el crecimiento humano. Cienc Saude Colet 1995;5(30):41-7.

3. WHO Expert Committee. Physical Status: The Use and Interpretation of Anthropometry. Series 854, Geneva: WHO; 1995. [Accessed on: September 27 ${ }^{\text {th }}, 2017$ ]. Available at: http: / / apps.who.int/iris/ bitstream/10665/37003/1/ WHO_TRS_854.pdf

4. Durán P, Merker A, Briceño G, et al. Colombian reference growth curves for height, weight, body mass index and head circumference. Acta Prdiatr 2016;105(3):e116-25.

5. Pawson I, Huicho L, Muro M, etal. Growth of children in two economically diverse Peruvian high-altitude communities. Am J Hum Biol 2001;13(3):323-40.

6. Cossio-Bolanos MA, Gomez-Campos R, Hespanhol JE, et al. Estudio del crecimiento físico de escolares a moderada altitud usando el área muscular del brazo por estatura y edad. Rev Andal Med Deporte 2013;6(2):66-72.

7. Cossio-Bolaños M, Gómez-Campos R, Andruske C, et al. Physical Growth, Biological Age, and Nutritional Transitions of Adolescents Living at moderate altitude in Peru. Int J Environ Res Public Health 2015;12(10):12082-94.

8. Kuczmarski R, Ogden C, Grummer-Strawn L, et al. CDC growth charts: United States. Advance Data 2000;314:1-28.

9. Fryar $\mathrm{CD}, \mathrm{Gu}$ Q, Ogden CL. Anthropometric reference data for children and adults: United States, 2007-2010. Vital Health Stat 2012;11(252):1-48.

10. World HealthOrganization. WHOChild GrowthStandards: Length/Height-for-Age, Weight-for-Age, Weight-forLength, Weight-for-Height and Body Mass Index-for-Age: Methods and development. Geneva:WHO;2006. [Accessed on: September 27th, 2017]. Available at: http: / / www.who. int/childgrowth/standards/Technical_report.pdf.

11. Lobstein T, Baur L, Uauy R. Obesity in children and young people: a crisis in public health. Obes Rev 2004;5(Suppl 1):4-104.

12. Rivera JA, González de Cossío T, Pedraza LS, et al. 
Childhood and adolescent overweight and obesity in Latin America: a systematic review. Lancet Diabetes Endocrinol 2014;2(4):321-32.

13. InternationalSociety forAdvancementofKinanthropometry (ISAK). International Standards for Anthropometric Assessment. Potchefstroom, RSA: ISAK, 2001. [Accessed on:September 27th, 2017]. Available at: http: / / www.ceap. $\mathrm{br} /$ material/MAT17032011184632.pdf.

14. Gómez-Campos R, de Arruda M, Hespanhol JE, et al. Referencial values for the physical growth of school children and adolescents in Campinas, Brazil. Ann Hum Biol 2015;42(1):62-9.

15. Bustamante B, Freitas D, Pan H, et al. Centile Curves and Reference Values for Height, Body Mass, Body Mass Index and Waist Circumference of Peruvian Children and Adolescents. Int J Environ Res Public Health 2015;12(3):2905-22.

16. Cole TJ, Bellizzi MC, Flegal KM, etal.Establishing a standard definition for child overweight and obesity worldwide: International survey. BMJ 2000;320(7244):1240-3.

17. Pan H, Cole TJ. LMSChartmaker. 2006. [Accessed on: March 28th, 2015. Available at: http:/ / www.healthforallchildren. co.uk.

18. Cossio-Bolaños MA, Viveros Flores A, Hespanhol JE, et al. Aplicabilidad del IMC en adolescentes escolares que viven a moderada altitud del Perú. Nutr Hosp 2015;31(2):922-7.

19. Cacciari E, MilaniS, Balsamo A, et al. Italian cross-sectional growth charts for height, weight and BMI (2 to $20 \mathrm{yr}$ ). J Endocrinol Invest 2006;29(7):581-93.

20. Urlacher SS, Blackwell AD, Liebert MA, et al. Physical Growth of the Shuar: Height, Weight, and BMI References for an Indigenous Amazonian Population. Am J Hum Biol 2016;28(1):16-30.

21. Flores-Huerta S. Antropometría, estado nutricio y salud de los niños. Importancia de las mediciones comparadas. Bol Med Hosp Infant Mex 2005;63(2):73-5.

22. Comité nacional de crecimiento y desarrollo. La Sociedad Argentina de Pediatría actualiza las curvas de Crecimiento de niñas y niños menores de cinco años. Arch Argent Pediatr 2008;106(5):462-7.

23. Cossio-Bolaños MA, Santi Maria T, Gomez Campos R, et al. The use of World Health Organization growth curves in children and adolescents that live in regions of moderate altitude. Rev Paul Pediatr 2012;30(3):314-20.
24. Fernández López JA, Remesar X, Alemany M. Ventajas teóricas del índice de Rohrer (P/A3) sobre el índice de masa corporal (P/A2) para la estimación de la adiposidad en humanos. Rev Esp Obes 2005;3(1):47-55.

25. Pietrobelli A, Faith MS, Allison DB, et al. Body mass index as a measure of adiposity among children and adolescents: a validation study. J Pediatr 1998;132(2):204-10.

26. Mei Z, Grummer-Strawn LM, Pietrobelli A, et al. Validity of body mass index compared with other body-composition screening indexes for the assessment of body fatness in children and adolescents. Am J Clin Nutr 2002;75(6):978-85.

27. WHO Multicentre Growth Reference Study Group. Assessment of differences in linear growth among populations in the WHO Multicentre Growth Reference Study. Acta Paediatr Suppl 2006;450:56-65.

28. De Onis M, Onyango AW, Van den Broeck J, et al. Measurement and standardization protocols for anthropometry used in the construction of a new international growth reference. Food Nutr Bull 2004;25(Suppl 1):S27-36

29. Grummer-Strawn LM, Garza C, Johnson CL. Childhood growth charts. Pediatrics 2002;109(1):141-2.

30. De Onis M. Growth curves for school age children and adolescents. Indian Pediatr 2009;46(6):463-5.

31. Roelants M,Hauspie R, Hoppenbrouwers K. References for growth and pubertal development from birth to 21 years in Flanders, Belgium. Ann Hum Biol 2009:36(6):680-94.

32. Fryar $\mathrm{CD}, \mathrm{Gu} Q$, Ogden $C L$, etal. Anthropometric reference data for children and adults: United States, 2011-2014. Vital Health Stat 2016;3(39):1-46.

33. Informe Sobre Desarrollo Humano 2013. El ascenso del Sur: Progreso humano en un mundo diverso. New York UNDP;2013. [Accessed on:September 27th, 2017]. Available at: http: / / www.undp.org/content/dam/undp/library / corporate/HDR/2013GlobalHDR/Spanish/HDR2013\%20 Report $\% 20$ Spanish.pdf.

34. Ponce de León S. The WHO Multicentre growth reference study and altitude above sea level. An example of hypsometric bias? High Alt Med Biol 2008;9(3):249-51.

35. Butte NF, Garza C, De Onis M. Evaluation of the feasibility of international growth standards for school-aged children and adolescents. Food Nutr Bul 2006;27(4 Suppl Growth Standard):S169-74. 